\title{
Wait times for psychiatric care in Ontario
}

\author{
Rachel Loebach, Sasha Ayoubzadeh \\ Faculty Reviewer: Javeed Sukhera, MD, FRCPC (Department of Psychiatry)
}

\section{ABSTRACT}

Mental illness is a prevalent and costly health care issue. Lengthy wait times for psychiatric services in Ontario are a barrier to adequate mental health care for adults, children and youth. The objective of this paper is to highlight the current state of psychiatric wait times in Ontario by looking at provincial policies and comparing data to physical health services, as well as between provinces and other developed nations. The Ontario government has successfully implemented mandatory reporting of wait-time data for many medical and surgical services. However, such policies have yet to be implemented for psychiatric services. As a result, availability of current data for comparison is limited. Nova Scotia is currently the only province to government mandate reporting of wait times for mental health. Furthermore, The Organisation for Economic Co-operation and Development ranks Canada below average on measures related to accessibility of psychiatric inpatient services compared to other developed nations. While Ontario has implemented new initiatives to address the issue of timely mental health care, there is still insufficient evidence to determine if they are effective. Continued advocacy for mandatory wait-time reporting at the provincial level and further analysis of current initiatives worldwide are essential steps toward reducing wait times.

\section{BACKGROUND}

The impact of mental illness in Canada is staggering. While mood disorders, such as depression, and anxiety are the most prevalent psychiatric illnesses, other disorders such as bipolar disorder, psychotic disorders and substance abuse are some of the many conditions that lead to personal distress and functional impairment. One in five people in Canada will experience a mental health issue in their lifetime. Mental illness cost the Canadian health care system a conservatively estimated $\$ 48.6$ billion in 2011 . Based on the current trajectory, a cumulative cost exceeding $\$ 2.3$ trillion is projected over the next 30 years. ${ }^{1}$ A significant portion of this cost includes productivity and work loss due to mental illness. Timely access to psychiatric services can therefore contribute to better economic and patient-related outcomes. ${ }^{2}$

Wait-time monitoring is the responsibility of provincial governments. The province of Ontario has been successful in reducing wait times for many priority medical services, in part by implementing mandatory wait-time reporting standards. ${ }^{3}$ This paper aims to outline the current state of wait-time reporting in Ontario and highlight disparities between physical and psychiatric conditions. The literature suggests early mental illness intervention is an important factor associated with improved outcomes. Such outcomes can vary from increasing the number of opportunities for effective treatment in people experiencing mental illness to reducing the number of relapses and rehospitalizations for patients receiving first-time treatment for psychosis., ${ }^{4,5}$

\section{CURRENT POLICY}

Government mandated legislation for the creation of benchmark targets, mandatory tracking, and reporting of wait times in psychiatry do not currently exist in Ontario. ${ }^{6}$ Meanwhile, wait-time targets have been in place for key health services including cardiac procedures, joint replacements, and numerous surgeries since 2005 when Ontario launched a wait-time strategy. The strategy called for mandatory tracking, reporting and publishing of wait-time data in a publicly accessible domain. Evidence-based benchmarks were created for target wait times in each of these areas. ${ }^{78}$ Shortly thereafter, similar strategies were employed by other provinces and data transparency allowed provincial providers and policy makers to compare and learn from one another. ${ }^{9}$ This has led to significant alterations in federal funding and consequently, the 2017 Ontario budget estimates that since 2005, approximately 322 million days of waiting have been saved for patients. ${ }^{10}$

The only widely accepted benchmark data available for psychiatry wait times in Canada dates back to 2006 when the Canadian Psychiatric Association (CPA) and Wait Time Alliance developed target timelines based on analysis of clinical evidence (Table 1). ${ }^{11}$

Table 1. Wait time benchmarks for psychiatric illness

CLASS TIME TARGETS

Emergent $^{\mathrm{a}} \quad$ within 24 hours for first episode psychosis, mania, major depression, and postpartum mood disorders

Urgent ${ }^{\mathrm{b}} \quad$ within 1 week for first episode psychosis, mania and postpartum mood disorders and 2 weeks for major depression

Scheduled $\quad$ within 2 weeks for first episode psychosis and 4 weeks for postpartum mood disorders and major depression

\footnotetext{
a immediate danger to life

${ }^{\mathrm{b}}$ unstable situation with potential for deterioration

'situation involving minimal pain ${ }^{11}$
} 
Some data regarding psychiatric wait times in Canada is available from the Fraser Institute, an independent research foundation. Waiting Your Turn is an annual report summarizing medical wait times for the fiscal year obtained by surveying physicians across specialties. In 2016, the overall response rate to the psychiatric survey was only $7.2 \%$ (compared to $21 \%$ for medical and surgical specialties). ${ }^{12}$ While this information may be useful for drawing rough comparisons; results must be interpreted with caution. Above all, the low response rate emphasizes the need for mandatory waittime reporting.

\section{PHYSICAL AND PSYCHIATRIC CONDITIONS}

During the five years following the launch of Ontario's waittime strategy, healthcare saw major improvements for cataract surgery (61\% reduction), hip replacements (53\% reduction), coronary angiography (51\% reduction) and cancer surgery (22\% reduction).$^{13}$ As of September 2016, Ontario scored above average on reaching wait-time targets compared to countrywide averages for many of these procedures. For example, $85 \%$ of hip replacements and $81 \%$ of knee replacements occurred within their respective timeframes in Ontario compared to national averages of $79 \%$ and $73 \%$, respectively. ${ }^{14}$

The best available estimates currently suggest wait-time averages for various psychiatric services generally fall outside of the recommended CPA timeframes. For example, the average wait for adult mental health counselling and treatment services is 45 days. For adult mood disorders, the average wait for outpatient services is 57 days and inpatient services is 47 days, well beyond the suggested 28 day standard. ${ }^{15}$ Children and youth populations wait even longer. A recent survey conducted by Children's Mental Health Ontario looked at wait times for patients age 6-18 in need of long-term counselling and intensive therapy. Across the province, wait times vary from 3 months up to 1.5 years. ${ }^{16}$

Furthermore, a recent study in Ontario reported only $63 \%$ of people who had been hospitalized for depression received a follow-up visit with a physician within 30 days after discharge, compared to $99 \%$ of people with heart failure. In those same 30 days, $25 \%$ of depressed patients either revisited the emergency department or were rehospitalized. ${ }^{17}$

Moreover, wait-time data for specific mental illnesses, such as eating disorder services, are of limited use without predetermined benchmarks. For example, there is currently an estimated 71 day wait for adult inpatient treatment and 34 day wait for outpatient counselling and treatment for eating disorders in Ontario. ${ }^{18}$ It is difficult to determine the consequences of such values and provide recommendations for improvement without adequate targets.

\section{COMPARING PROVINCES}

The only province in Canada that government mandates waittime reporting in any capacity for mental health services is Nova Scotia. Beginning in 2014, wait times are measured as the time between receipt of an elective patient referral to a community-based mental health service and the date of the first appointment. Bear- ing in mind the 28-day CPA standard, data from 2016 demonstrated that $50 \%$ of adults were seen within 33-42 days and 90\% were seen within 97-106 days. Again, young people waited longer than adults as $50 \%$ of children were seen within $36-61$ days and $90 \%$ within 109-127 days. ${ }^{19}$

Open Minds, Healthy Minds: Ontario's Comprehensive Mental Health and Addictions Strategy is a multidisciplinary strategy that was launched in 2011 to improve mental health services for Ontarians. The plan specifies an approach for improving care by expanding mental health facilities, training healthcare workers, and targeting efforts in specific demographics, including children and Indigenous communities. Similar initiatives also exist in other provinces. However, until updated target wait times are established, data will continue to be insufficient to properly evaluate the success of such programs. ${ }^{20}$

\section{COMPARING COUNTRIES}

According to data from the Organisation for Economic Co-operation and Development (OECD), Canada falls below average among developed countries with respect to access to inpatient psychiatric services. A 2011 report on number of psychiatric beds per 1000 population ranks Canada 27 out of 34 among OECD countries. Several European countries including the Netherlands, Germany, and the Czech Republic rank near the top. Australia and England also rank higher than Canada, although they too fall below the average. $^{21}$

Unfortunately, information regarding wait times for psychiatric care among OECD countries is not available. A 2014 report, Measuring and Comparing Health Care Waiting Times in OECD Countries, details numerous wait-time trends including joint replacements, cataract surgeries and multiple modes of medical imaging. However, there is no mention of psychiatric services in the report. ${ }^{22}$

Like Ontario and other Canadian provinces, many nations are implementing unique strategies to improve timely access to mental health care. One example is England. The National Health Society and Department of Health put forth "Improving access to mental health services by 2020", a publication aiming to ensure mental and physical health services are given equal priority in terms of timely access to care. The strategy provides guidance as to how new standards for mental health wait-time reporting can be implemented and is well underway. ${ }^{23}$ Currently, wait-time information for treatment of first episode psychosis and eating disorders is already available to the public. ${ }^{24,25}$ England's approach uses clear goal setting and effectiveness tracking to achieve measurable improvements in quality and access to psychiatric care. ${ }^{23}$ Information regarding outcomes of this strategy as it becomes available may be beneficial for use by other countries, including Canada.

\section{SUMMARY}

Poor outcomes are associated with delayed treatment for psychiatric illnesses. The importance of addressing the issue of long wait times for mental health care in Canada is becoming increasingly apparent. The Ontario government has yet to mandate provi- 
sional reporting of wait-time data despite significant success in this area for numerous medical and surgical services. Improving access to mental health care is a challenge for all Canadians; the importance of collaboration at all levels cannot be overstated.

\section{REFERENCES}

1. Smetanin P, Stiff D, Briante C, et al. The Life and Economic Impact of Major Mental Illnesses in Canada: 2011 to 2041. Toronto, ON:RiskAnalytica, on behalf of the Mental Health Commission of Canada. 2011 Dec [cited 4 May 2017]. Available from: http://www.mentalhealthcommission.ca/sites/default/files/MHCC_Report_Base_Case_FINAL_ENG_0_0.pdf.

2. Lim KL, Jacobs P, Ohinmaa A, et al. A new population-based measure of the burden of mental illness in Canada. Chronic Dis Can. 2008 Feb;28(3):92-8.

3. Canadian Institute for Health Information. Wait time for priority procedures in Ontario, 2017. [Internet] Ottawa, ON: Canadian Institute for Health Information; 2017 Mar 1 [cited 2017 May 31]. Available from https://www.cihi.ca/sites/default/files/document/wait-timesreport-2017_en.pdf.

4. Ansell D, Crispo JA, Simard B, et al. Interventions to reduce wait times for primary care appointments: a systematic review. BMC Health Serv Res. 2017 Apr 20;17(1):295.

5. Lieberman JA, Perkins D, Belger A, et al. The early stages of schizophrenia: speculations on pathogenesis, pathophysiology, and therapeutic approaches. Biol Psychiatry. 2001 Dec 1;50(11):884-97.

6. Wait Time Alliance. Eliminating Code Gridlock in Canada's Health Care System: 2015 Wait Time Alliance Report Card. [Internet]. Ottawa, ON: Wait Time Alliance; 2015 June [cited $2017 \mathrm{Feb} 27$ ]. Available from: http://www.waittimealliance.ca/wp-content/uploads/2015/12/EN-FINAL-2015-WTA-Report-Card_REV.pdf.

7. Ministry of Health and Long Term Care. First ever common benchmarks will allow Canadians to measure progress in reducing wait times. [Internet]. Toronto, ON; 2005 Dec 12 [cited 2017 May 30]; Available from:

8. https://news.ontario.ca/archive/en/2005/12/12/First-ever-commonbenchmarks-will-allow-Canadians-to-measure-progress-in-reducin. html.

9. Canadian Intergovernmental Conference Secretariat. A 10-Year Plan to Strengthen Health Care. [Internet]. Ottawa, ON. 2004 Sept [cited 2017 May 30]. Available from: http://www.scics.gc.ca/CMFiles/800042005 elJXB-342011-6611.pdf.

10. Wait Time Alliance. Time to Close the Gap: Report Card on Wait Times in Canada. [Internet] Ottawa, ON: Wait Time Alliance; 2014 June [cited $2017 \mathrm{Feb} 27$ ]. Available from: http://www.waittimealliance. ca/wp-content/uploads/2014/06/FINAL-EN-WTA-Report-Card.pdf.

11. Government of Ontario. [Internet]. 2017 Ontario Budget: A Stronger, Healthier Ontario, Chapter IV: Reducing Wait Times. Ottawa, ON. 2017 [cited 2017 May 30]. Available from: http://www.fin.gov.on.ca/en/budget/ontariobudgets/2017/ch4a.html\#a4.

12. Canadian Psychiatric Association. Wait Time Benchmarks for Patients With Serious Psychiatric Illnesses, A series of recommendations made by Canada's psychiatrists. [Internet]. Ottawa, ON: Canadian Psychiatric Association; 2006 [cited $2017 \mathrm{Feb} 27$ ]. Available from http://www. cpa-apc.org/wp-content/uploads/Wait_times-CPA_policy_paper_lweb-EN.pdf.

13. Fraser Institute. Waiting your turn: Wait times for health care in Canada, 2016 report. [Internet]. Vancouver, BC: Fraser Institute; 2016 Nov 23 [cited 2017 Mar 7]. Available from: https://www.fraserinstitute. org/sites/default/files/waiting-your-turn-wait-times-for-health-carein-canada-2016.pdf.

14. Ministry of Health and Long-Term Care. [Internet] Ontario Wait Time Strategy. Toronto, ON: Ministry of Health and Long-Term Care; 2010
July 17 [cited $2017 \mathrm{Feb} 25]$. Available from: https://news.ontario.ca/ mohltc/en/2010/06/ontarios-wait-time-strategy.html.

15. Wait Times for Priority Procedures in Canada, 2017. [Internet]. Ottawa, ON: Canadian Institute for Health Information; 2017 Mar 23 [cited 2017 May 4]. Available from: https://www.cihi.ca/sites/default/files/ document/wait-times-report-2017_en.pdf.

16. ConnexOntario Health Services Information. Average Wait in Days for Mental Health Services in Ontario by Service Category, Average Wait in Days for Services that are Restricted to or Specialized for Mood Disorders. [Data extracted from the ConnexOntario Database on 2017 Mar 8].

17. Children's Mental Health Ontario via Ministry of Children and Youth Services. Child and Youth Mental Health. [Internet]. Toronto, ON: Children's Mental Health Ontario, 2016 Nov 26 [cited 2017 Mar 30]. Available from: http://www.auditor.on.ca/en/content/annualreports/ arreports/en16/v1_301en16.pdf.

18. Lin E, Diaz-Granados N, Stewart DE, et al.. Postdischarge care for depression in Ontario. Can J Psychiatry. 2011 Aug;56(8):481-9.

19. ConnexOntario Health Services Information. Average Wait in Days for Mental Health Services in Ontario by Service Category, Average Wait in Days for Services that are Restricted to or Specialized for Eating Disorders. [Data extracted from the ConnexOntario Database on 2017 Mar 8].

20. Nova Scotia Wait Times. [Internet]. Government of Nova Scotia, 2017 [cited 2017 May 14]. Available from: https://waittimes.novascotia.ca/ procedure/mental-health-adult-community-based-services\#trends.

21. Ministry of Health and Long Term Care. [Internet]. Open Minds, Healthy Minds; Ontario's Comprehensive Health and Addictions Strategy. Toronto, ON; 2011 June [cited 2017 Mar 20]; Available from: http://www.health.gov.on.ca/en/common/ministry/publications/reports/mental_health2011/mentalhealth_rep2011.pdf.

22. 21 Hewlett $\mathrm{E}$ and Horner K. Mental Health Analysis Profiles (MhAPs): England, UK. [Internet]. Paris, FR: OECD Health Working Papers. 2015 July [cited 2017 Mar 30]. Available from: http://www.oecd.org/ officialdocuments/publicdisplaydocumentpdf/?cote=DELSA/HEA/ WD/HWP(2015)4\&docLanguage=En.Siciliani L, Borowitz M, Moran V. Measuring and comparing health care waiting times in OECD countries. Health Policy. 2014 Dec;118(3):292-303.

23. National Health Service England, Medical Doctorate and Mental Health Team. [Internet]. Guidance to support the introduction of access and waiting time standards for mental health services in 2015/16. London, UK. 2015 Feb 12 [cited 2017 May 14]. Available from: https:// www.england.nhs.uk/wp-content/uploads/2015/02/mh-access-waittime-guid.pdf

24. National Health Service England. Statistical work areas, Early Intervention in Psychosis Waiting Times. [Internet]. NHS England Database [cited 2017 May 14]. Available from: https://www.england.nhs.uk/ statistics/statistical-work-areas/eip-waiting-times/.

25. National Health Service England. Statistical work areas, Children and Young People with an Eating Disorder Waiting Times. [Internet]. NHS England Database [cited 2017 May 14]. Available from: https://www. england.nhs.uk/statistics/statistical-work-areas/cyped-waiting-times/. 